\title{
Influence of Curing Regimes on Engineering and Microstructural Properties of Geopolymer-Based Materials from Water Treatment Residue and Fly Ash
}

\author{
Nguyen Hoc Thang1, Bui Khac Thach², Do Quang Minh²* \\ ${ }^{1}$ Faculty of Chemical Technology, Ho Chi Minh City University of Food Industry, 140 Le Trong Tan Street, Tay \\ Thanh Ward, Tan Phu District, Ho Chi Minh City, 700000, Viet Nam \\ ${ }^{2}$ Faculty of Materials Technology, Ho Chi Minh City University of Technology (HCMUT) - Vietnam National \\ University (VNU), 268 Ly Thuong Kiet Street, Ward 14, District 10, Ho Chi Minh City, 700000, Viet Nam
}

\begin{abstract}
Geopolymerization is a new method for treating water treatment residue (WTR) from water purification plants to reduce the amount of stored land in urban areas. Polymeric bond formation depends on the curing conditions. In this study, the curing conditions suitable for subsequent treatment to save energy consumption and production costs in the future application were investigated. The WTR had a high aluminosilicate content with low alkaline activity, so fly ash (FA) was added to FA and WTR mixtures in the ratio of 40 and 60 weight percent (\% in wt.), respectively. The moisture content of the mixtures ranged in $12-15 \%$, suitable for semi-dry pressing to form pellets. After this formation, the geopolymer samples were cured under different conditions (room temperature, microwave oven, in dryer at $110^{\circ} \mathrm{C}$, and in autoclave with hydrothermal condition). The experimental results showed that the hydrothermal samples had better properties, such as $\mathrm{pH}<9$, high stability of mechanical strength over $3.5 \mathrm{MPa}$, and soft coefficient over 0.75 . The microstructural properties were investigated using modern analytical tools, such as XRD, SEM, FTIR, and NMR, to detect the chemical functional groups of the aluminosilicate networks in the geopolymer matrix and the close relationship among the properties and its microstructure.
\end{abstract}

Keywords: Dryer; Fly ash; Geopolymer-based materials; Hydrothermal; Microwave oven; Water treatment residues

\section{Introduction}

The geopolymerization process involves chemical reactions of aluminosilicates $\left(\mathrm{Al}^{3+}\right.$ with coordinate number 4 ) with alkaline polysilicate networks for the formation of $\mathrm{Si}-\mathrm{O}-\mathrm{Al}$ bonding (Davidovits, 2020). The geopolymerization products have three-dimensional structural frameworks with the chemical formula as follows:

$$
\mathrm{Mn}_{\mathrm{n}}\left[-\left(\mathrm{SiO}_{2}\right)_{\mathrm{z}}-\mathrm{AlO}_{2}\right]_{\mathrm{n}} \cdot \mathrm{WH}_{2} \mathrm{O}
$$

where $\mathrm{M}$ is the metal cations of $\mathrm{K}^{+}, \mathrm{Na}^{+}, \mathrm{Ca}^{2+}$, and others, $\mathrm{n}$ is the degree of condensation, and $\mathrm{z}=1,2,3$, or $>>3$. The cations of $\mathrm{Na}^{+}, \mathrm{K}^{+}, \mathrm{Ca}^{2+}$, and others equalize the anions of $\left[\mathrm{AlO}_{4}\right]^{5-}$ and $\left[\mathrm{SiO}_{4}\right]^{4-}$. The chain and ring structures are formed and networked together based on Si-0-Al sialate bridges (Davidovits, 2020). The geopolymer-based materials were developed based on the new bonding circuits of Q3 and Q4, as known from the reports of 
nuclear magnetic resonance (NMR) analyses (Giannopoulou and Panias, 2007; Davidovits, 2020; Rim et al. 2020).

The geopolymer structures are the tetrahedra [SiO4 $]^{4-}$ surrounded by four, three, two, one, or non-tetrahedra [AlO4] ${ }^{5-}$ (Davidovits, 2020; Rim et al., 2020). The bonding circuit forming units are denoted as $\mathrm{Q} 4(\mathrm{nAl})$ with $\mathrm{n}=0,1,2,3$, and 4 corresponding to the number

of tetrahedra of [AlO4] ${ }^{5-}$ or $\mathrm{Q}$ represents the [SiO4] $]^{4-}$ tetrahedra. In the ${ }^{29} \mathrm{Si}$ nuclear magnetic resonance spectrum ( $\left.{ }^{29} \mathrm{Si} \mathrm{NMR}\right), \mathrm{Q} 4(4 \mathrm{Al})$ peaked at 83-88 ppm, Q4(3Al) at 88-94 ppm, Q4(2Al) at 91-98 ppm, Q4(1Al) at 96-105 ppm, and Q4(0Al) at 103-113 ppm (Rim et al. 2020).

Geopolymer-based materials with amorphous phases can transform into crystals known as zeolites when they are supplied suitable energy under known conditions of high temperature and pressure (Zhang et al., 2008). The XRD patterns of geopolymer-based materials with amorphous structural frameworks changed at similar diffraction peaks of zeolite crystals (Davidovits, 2020; Sudibandriyo and Putri, 2020).

Rapid urbanization impedes the use of large land areas to contain water treatment residues (WTR) from water purification plants. Finding new solutions to manage and treat this waste is imperative. Geopolymerization is a new method developed in the last decade to treat waste, such as WTR, from water purification plants (Luukkonen et al., 2019; Numanuddin et al., 2021).

The products based on WTR have very low strength (Waijarean et al., 2013; Geraldo et al., 2017) due to the weak alkaline activity of WTR. Therefore, WTR treatment should be combined with materials of high activity, such as FA (Suksiripattanapong et al., 2015 Horpibulsuk et al., 2016; Janani and Santhi, 2018; Susanto et al., 2020), metakaolin (Geraldo et al., 2017), rice husk ash (Waijarean et al., 2014; Poowancum et al., 2015), and others (Nguyen, 2020a; Nguyen, 2020b; Do et al., 2020a; Do et al., 2020b; Nguyen, 2021, Petrus et al., 2021).

When the samples are cured in an autoclave under high pressure and temperature conditions, the alkaline activators dissolve $\mathrm{SiO}_{2}$ and $\mathrm{Al}_{2} \mathrm{O}_{3}$ faster. The $\mathrm{H}_{2} \mathrm{O}$ molecules supply $[\mathrm{OH}]^{-}$to enter into the structures of $\mathrm{Na}_{2} \mathrm{O}, \mathrm{SiO}_{2}$, and $\mathrm{Al}_{2} \mathrm{O}_{3}$; hence, this is called hydrothermal process. Finally, at atmospheric pressure, the water is removed from the structures to form polymer bonds in the geopolymer-based material by drying (Alas and Ali, 2019; Nguyen, 2021; Nguyen and Dang, 2021; Nguyen et al., 2021a; Nguyen et al., 2021b).

Swanepoel and Strydom (2002) suggested that the optimal condition for strength development of geopolymer samples is at $60^{\circ} \mathrm{C}$ for $48 \mathrm{~h}$. Palomo et al. (2004) concluded that geopolymer samples based on fly ash (FA) were cured at $65^{\circ} \mathrm{C}$ for one week or $85^{\circ} \mathrm{C}$ for 24 $\mathrm{h}$, which had enough energy to achieve levels of reactions and strength responding to the engineering requirements. However, when the temperature was over $60^{\circ} \mathrm{C}$, the strength of specimens decreased. Adam and Horianto (2014) revealed that the curing temperature range of $80-120^{\circ} \mathrm{C}$ for $20 \mathrm{~h}$ had better strength than that of curing for 4 and $6 \mathrm{~h}$. The geopolymer-based materials cured in microwave conditions are a new method in a short time from 1 to $7 \mathrm{~min}$. The microwave conditions accelerate the reaction and hardening processes while participating in water elimination reactions (Do et al., 2020a).

The mechanical strength of geopolymer-based materials increases with an increase in alkali concentration from 4 to $10 \mathrm{M}$ (Prasanphan et al., 2019). In the concentration range from 10 to $18 \mathrm{M}$, the strength of the geopolymer gradually decreased (Alonso and Palomo, 2001). This parallels the experimental results of Mustafa et al. (2012), which revealed increased strength of the geopolymer specimens that used alkali solution from 6-12 M, while the geopolymer samples that used alkali concentration from 12-16 M decreased in strength. The $\mathrm{pH}$ values in 13-14 are best for forming geopolymeric networks with good 
mechanical properties. The ratios of $\mathrm{M}_{2} \mathrm{O} / \mathrm{SiO}_{2}, \mathrm{SiO}_{2} / \mathrm{Al}_{2} \mathrm{O}_{3}, \mathrm{H}_{2} \mathrm{O} / \mathrm{M}_{2} \mathrm{O}$, and $\mathrm{M}_{2} \mathrm{O} / \mathrm{Al}_{2} \mathrm{O}_{3}(\mathrm{M}$ is $\mathrm{Na}$ or $\mathrm{K}$ ) range from 0.2 to $0.48,3.3$ to $4.5,10$ to 25 , and 0.8 to 1.6 , respectively (Nguyen, 2020a).

Geopolymers from WTR have many potential applications in building materials, water and wastewater treatment, including adsorbents/ion exchangers, membranes and filter, catalysts, stabilizers of water and WTR (Luukkonen et al., 2019), pH regulators (Novais et al., 2016; Ascensão et al., 2017), and others. The geopolymer materials are considered the materials of the 21st century due to their zero $\mathrm{CO}_{2}$ emissions in the manufacturing process and their high mechanical strength.

Therefore, in this study, experiments were conducted to produce geopolymer-based materials using industrial solid wastes of WTR and FA. The products were cured under various conditions to determine their engineering properties. Also, the $\mathrm{pH}$ values of the geopolymer were tested to assess their impact on the environment. The microstructural properties of the materials were characterized and evaluated using the analytical tools of X-ray diffraction (XRD), Fourier transform infrared spectroscopy (FTIR), scanning electron microscope (SEM), and nuclear magnetic resonance spectroscopy (MNR) to confirm polymeric bond formation in the geopolymer-based material.

\section{Materials and Methods}

\subsection{Specifications of the Raw Materials}

This study used WTR from Thu Duc Water Purification Plant, Ho Chi Minh City, and FA was from Vinh Tan 2 Thermal Power Plant in Binh Thuan province, Vietnam. The WTR and FA had average particle sizes of $25.2 \mu \mathrm{m}$ and $58.6 \mu \mathrm{m}$, respectively. Their chemical compositions were analyzed using X ray fluorescence (XRF) (Table 1).

Table 1 Chemical composition (\%, in wt.) of raw materials using X ray fluorescence (XRF)

\begin{tabular}{lllllllllll}
\hline Materials & $\mathrm{SiO}_{2}$ & $\mathrm{Al}_{2} \mathrm{O}_{3}$ & $\mathrm{Fe}_{2} \mathrm{O}_{3}$ & $\mathrm{~K}_{2} \mathrm{O}$ & $\mathrm{Na}_{2} \mathrm{O}$ & $\mathrm{CaO}$ & $\mathrm{MgO}$ & $\mathrm{TiO}_{2}$ & Others & LOI \\
\hline WTR & 40.09 & 30.49 & 9.33 & 1.00 & 0.02 & 0.19 & 0.10 & 1.39 & 0.36 & 17.03 \\
FA & 51.84 & 24.40 & 5.64 & 2.95 & 0.24 & 3.46 & 0.64 & 1.11 & 1.15 & 8.57 \\
\hline
\end{tabular}

\subsection{Methodologies}

This study used a blend ratio to produce geopolymer samples. Raw materials were mixed in ratios of $6 \mathrm{~kg}$ WTR, $4 \mathrm{~kg} \mathrm{FA}$, and $0.48 \mathrm{~kg} \mathrm{NaOH}$. The amount of water was $15.07 \%$ (in weight) and mixed for 15 min using a ball mill. After thorough mixing, the mixture was formed in a roller press. The powder was pressed via roller press to form pellets about 10 $\mathrm{mm}$ and $20 \mathrm{~mm}$ in diameter and length. The samples were cured in the different curing regimes as follows: At room temperatures with humidity at $80-85 \%$ and temperature of $25-30^{\circ} \mathrm{C}$ cured for $3,7,14,21$, and 28 days to test for engineering and microstructural properties; In the dryer (Venticell) at temperature of $110^{\circ} \mathrm{C}$ for $14 \mathrm{~h}$. Then, the samples were cured at room temperature for $3,7,14,21$, and 28 days to test for engineering and microstructural properties; In a microwave (Sanyo EM-S2182W) with a power capacity of $120 \mathrm{~W}$ for $5 \mathrm{~min}$. The samples were continuously cured at room temperature for $3,7,14$, 21, and 28 days to test for engineering and microstructural properties; In hydrothermal conditions using autoclave equipment at a temperature of $180^{\circ} \mathrm{C}$ for $8 \mathrm{~h}$. After that, the samples were continuously cured at room temperature for $3,7,14,21$, and 28 days to test for engineering and microstructural properties.

The non-deformed geopolymer samples were selected for testing engineering properties, such as compressive strength, soft coefficient, and $\mathrm{pH}$ values at curing days of 3 , 
$7,14,21$, and 28 . The pH values were measured daily during the curing time following the standard of ASTM D3987-12 (2020) using the Hanna Instruments HI221 pH meter. The softening coefficient was tested following the Vietnamese standard of TCVN 9362-2012. The geopolymer specimens with the best engineering properties after curing for 28 days were characterized for microstructural properties using FTIR (Thermo ARL ADVANT'X equipment), XRD (Bruker D8 Advanced equipment), SEM (FE-SEM S4800 Hitachi equipment), and NMR (JEOL 400MHz NMR equipment).

\section{Results and Discussion}

\subsection{Engineering Properties of Geopolymer-based Materials}

Figure 1 shows that the geopolymer-based materials changed regarding the volumetric weight of samples during the cured time. The volumetric weight of the autoclave samples decreased continuously from 2.07 to $1.88 \mathrm{~g} / \mathrm{cm}^{3}$ after curing for 28 days. The samples cured in the dryer and microwave oven significantly reduced the volumetric weight for the first 7 days at 1.96 and $1.98 \mathrm{~g} / \mathrm{cm}^{3}$, respectively. After that, their volumetric weights increased over $2.00 \mathrm{~g} / \mathrm{cm}^{3}$ after curing for 28 days. This is related to the absorption of water from the air or the reaction with $\mathrm{CO}_{2}$ of the free alkali. The experimental results also show that the geopolymer samples cured in hydrothermal conditions using an autoclave had higher stability, uniformity, and quality.

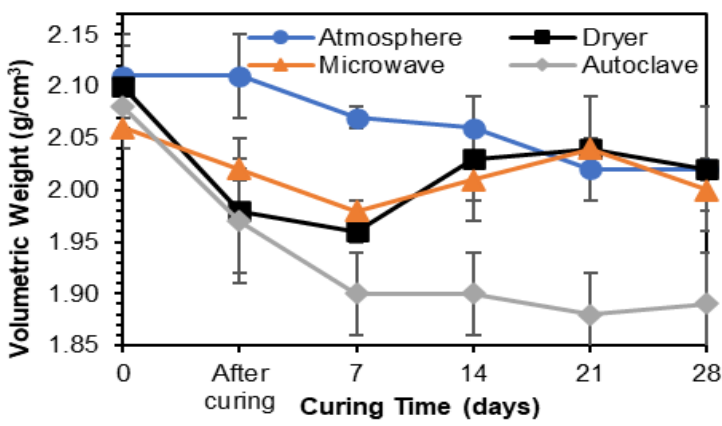

Figure 1 Volumetric weight $\left(\mathrm{g} / \mathrm{cm}^{3}\right)$ of the samples depending on curing time

The geopolymer samples continuously decreased regarding $\mathrm{pH}$ values during the curing time (Figure 2). The samples cured in hydrothermal conditions using autoclave had the lowest $\mathrm{pH}$ values of 8.67 for 14 days and 8.88 for 28 days because these samples reacted to the best geopolymerization. However, the $\mathrm{pH}$ value gradually decreased in the first days and hardly changed from 21 to 28 days. The decrease in $\mathrm{pH}$ is also related to the reaction of $\mathrm{CO}_{2}$ in the air and water to form $\mathrm{H}_{2} \mathrm{CO}_{3}$ on the sample surfaces:

$$
\mathrm{H}_{2} \mathrm{O}+\mathrm{CO}_{2} \rightarrow \mathrm{H}_{2} \mathrm{CO}_{3}
$$

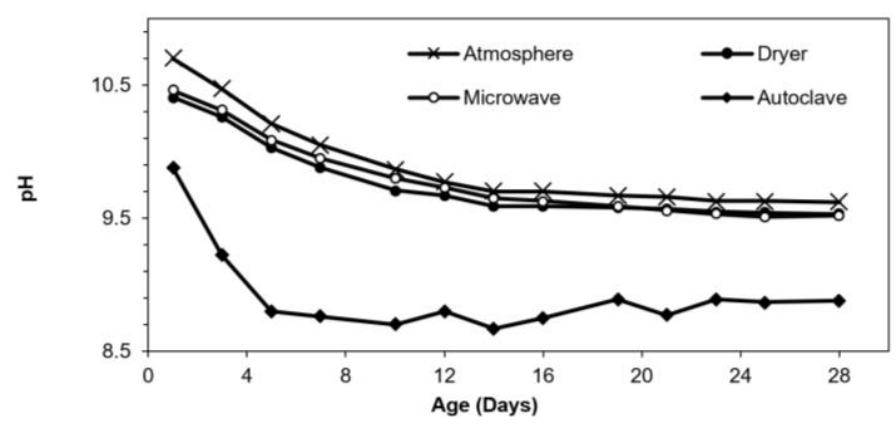

Figure $2 \mathrm{pH}$ values of the samples depending on curing time 
The initial $\mathrm{pH}$ of the samples was mainly due to the diffusion of $\mathrm{Na}^{+}$ions (Silva et al., 2010). For the samples cured in hydrothermal conditions, the $\mathrm{pH}$ value was below that of the samples cured in the other conditions because of the zeolite formation in the hydrothermal reactions. The zeolite kept the $\mathrm{Na}^{+}$cations in its structure (Lee et al., 2000).

Figure 3 shows that the geopolymer-based materials changed the compressive strength during the curing time. The compressive strength of samples cured at 28 days significantly exceeded that of the samples cured at 3 and 7 days. The samples cured in the dryer (at a temperature of $110^{\circ} \mathrm{C}$ for $14 \mathrm{~h}$ ) after 28 days had the highest compressive strength related to forming a new aluminosilicate structural lattice in the geopolymer-based materials. Notably, the minimum mechanical strength value of the unburned brick is $3.5 \mathrm{MPa}$, as required in the Vietnamese standard of TCVN 6477-2006.

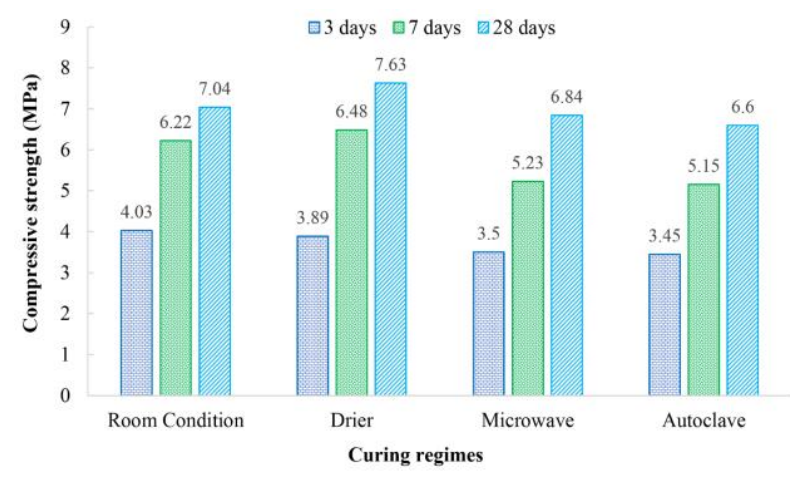

Figure 3 Changes in compressive strength of the geopolymer samples during curing time

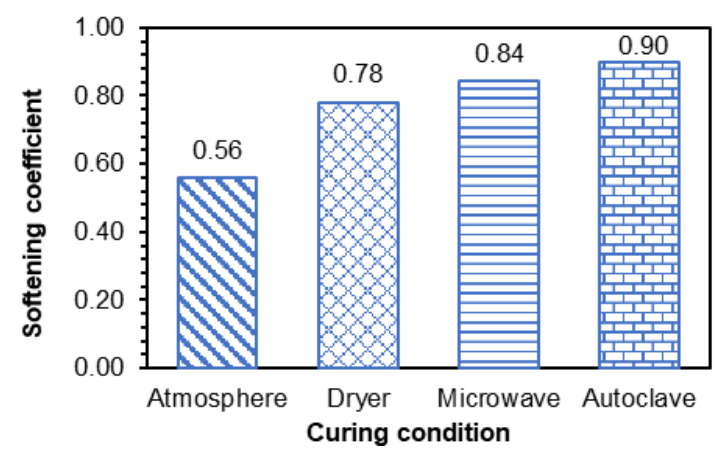

Figure 4 Softening coefficient of the samples in the various curing regimes after 28 days

Figure 4 shows the softening coefficient values of the samples. The samples cured at room temperature had the lowest softening coefficient value of 0.56 . Other geopolymer samples had softening coefficient values from 0.78 to 0.90 , meeting the requirements of the TCVN 9362-2012 Vietnamese standard for unburnt building materials. Notably, the materials had high strength in wet conditions, with the softening coefficient reaching approximately 1 .

\subsection{Microstructural and Morphological Characteristics of Geopolymer-based Materials}

Figure 5 shows the XRD patterns of samples cured in the different conditions compared to the XRD patterns of raw materials (FA and WTR). The XRD patterns of the samples show the amorphous structural features of the aluminosilicate bonding networks in a geopolymeric network matrix. Furthermore, in the narrow range around the diffraction angle of 2-Theta at $26^{\circ}$, there were changes in the diffraction peak intensity of FA and WTR 
to form an analcime crystal with 2 -Theta at $25.95^{\circ}$ and $26.02^{\circ}$, as shown in PDF 00-0760901.

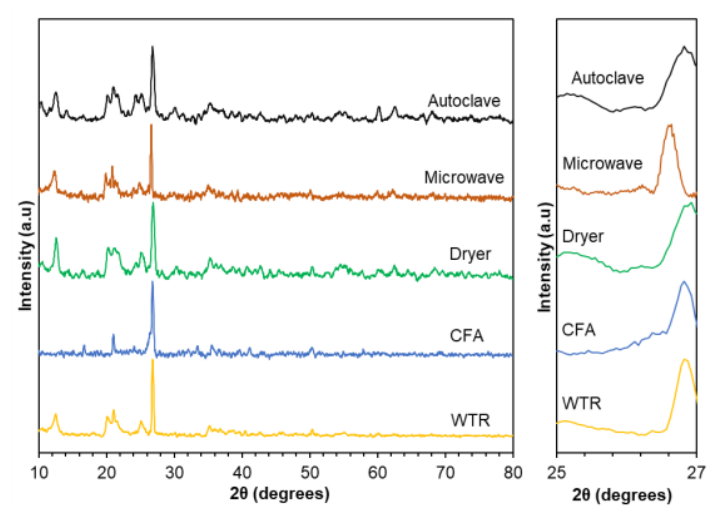

Figure 5 XRD patterns of WTR, FA, and the samples cured in different conditions

This is evident in geopolymer formation (Davidovits, 2020; Nguyen et al., 2020a; Nguyen et al.,2020b; Nguyen, 2021). In addition, crystals such as quartz ( $\left.\mathrm{SiO}_{2}\right)$, kaolinite $\left(\mathrm{Al}_{2} \mathrm{O}_{3} .2 \mathrm{SiO}_{2} .2 \mathrm{H}_{2} \mathrm{O}\right)$, hematite $\left(\mathrm{Fe}_{2} \mathrm{O}_{3}\right)$, and mullite $\left(3 \mathrm{Al}_{2} \mathrm{O}_{3} .2 \mathrm{SiO}_{2}\right)$ still exist, as is known in the initial raw materials.

The FTIR spectra in Figure 6 detected asymmetrical elastic oscillation regions of Si-0$\mathrm{T}$ bonding (in which $\mathrm{T}$ represents $\mathrm{Si}$ or $\mathrm{Al}$ ) (Panias et al., 2006). This oscillation region is within the wavenumbers from 1100 to $900 \mathrm{~cm}^{-1}$ (Schoonheydt et al., 2018; Nguyen et al., 2020b; Nguyen, 2021). The geopolymer formation displaced the absorption peak position of the Si-O-T bonding toward the lower frequency. This is due to the replacement of $\mathrm{Al}^{3+}$ ions in the aluminosilicate structural networks (Schoonheydt et al., 2018).

In the wavenumber range of $950-1100 \mathrm{~cm}^{-1}$, there is the displacement of absorption peaks at $1010.52 \mathrm{~cm}^{-1}$ and $1033.69 \mathrm{~cm}^{-1}$ in the geopolymer samples, and it is below that of reference sample. It is related to the dissolution of the activated $\mathrm{SiO}_{2}$ and $\mathrm{Al}_{2} \mathrm{O}_{3}$ from the raw materials into alkaline solution, forming the amorphous structure of the aluminosilicate gel in the geopolymeric network (Lee et al., 2000; Nguyen, 2020a). This is evident for restructuring after the aluminosilicates were dissolved in alkaline solution to form Si-O-Al bonds in the inorganic polymer chains (Davidovits, 2020; Nguyen, 2021).

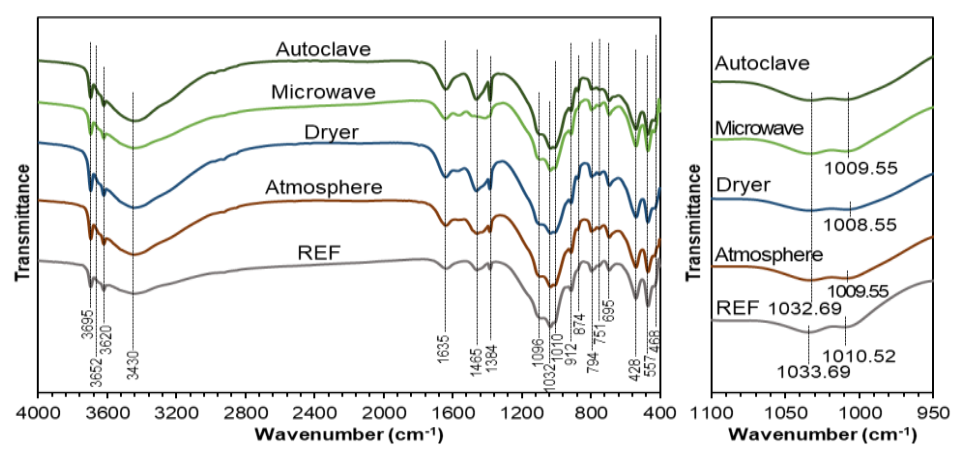

Figure 6 FTIR spectra of the geopolymer samples cured in drier, microwave, and autoclave at room conditions and the FTIR spectrum of the reference geopolymer sample

Two geopolymer samples cured in autoclave and dryer conditions were selected to analyze and evaluate the microstructure and morphological characteristics using SEM (Figure 7). At a magnification of 5000 times, the gel structure of the geopolymer is detected like that of Alehyen et al. (2017). The gel layers appeared more for the samples cured in 
autoclave conditions with a better geopolymerization. Besides, the needle-shaped (N) structures are easily detected for the geopolymer cured in the autoclave surrounding FA ball particles. Several pores (P) were formed by the cleavage and dissolution of FA particles. The reacted FA (RFA) and unreacted FA (UFA) are easily seen in SEM images.

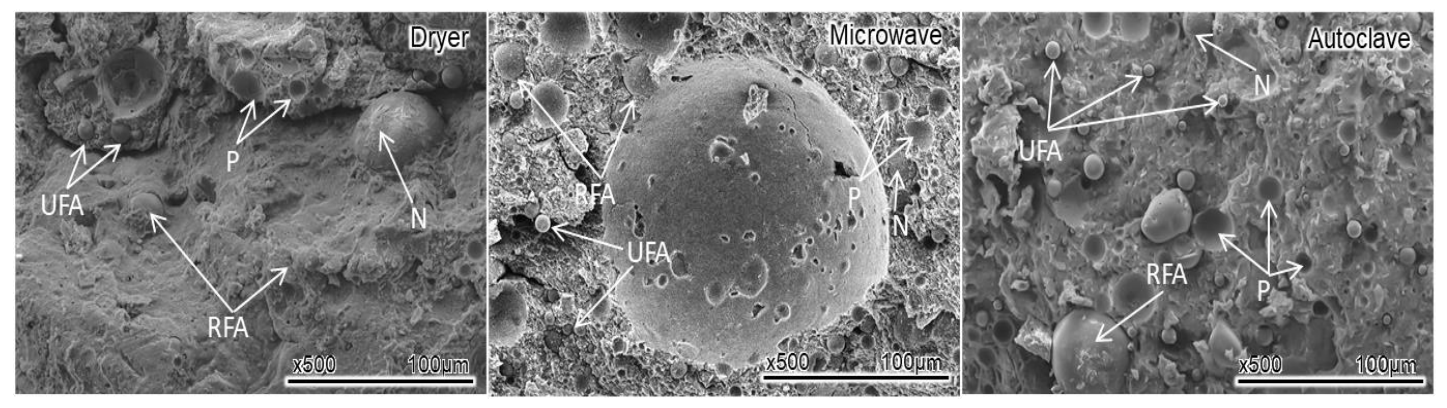

Figure 7 Microstructural and morphologies characteristics of the geopolymer samples cured in drier and autoclave conditions at magnifications of 500 and 5000 times

Figure 8 shows the ${ }^{29} \mathrm{Si}$ NMR spectra of the samples cured in a dryer at $110^{\circ} \mathrm{C}$, microwave oven, and hydrothermal conditions after 28 days. The NMR signals at $-74.7 \mathrm{ppm}$ (for the sample cured in a microwave oven), $-72.6 \mathrm{ppm}$ (for the sample cured in a dryer at $110^{\circ} \mathrm{C}$ ), and $-71.2 \mathrm{ppm}$ (for the sample cured in an autoclave) are monosilicate structures corresponding to $\mathrm{Q}_{0}$ type. The MNR signals at $-77.7 \mathrm{ppm}$ (for the sample cured in a microwave oven), $-76.4 \mathrm{ppm}$ (for the sample cured in a dryer at $110^{\circ} \mathrm{C}$ ) and $-77.6 \mathrm{ppm}$ (for the sample cured in an autoclave) are disilicate or sorosilicate structures or the end of the structural chains corresponding to the $\mathrm{Q}_{1}$ type (Duxson et al., 2005; Protsak et al., 2019; Rim et al., 2020). The chemical shift from -80 to $-100 \mathrm{ppm}$ is related to the $\left[\mathrm{SiO}_{4}\right]^{4-}$ tetrahedra surrounded by a different number of $\left[\mathrm{AlO}_{4}\right]^{5-}$ tetrahedra (Rim et al., 2020; Duxson et al., 2007). The NMR results are listed in Table 2 with the peaks corresponding to the different structural types in the geopolymeric networks.

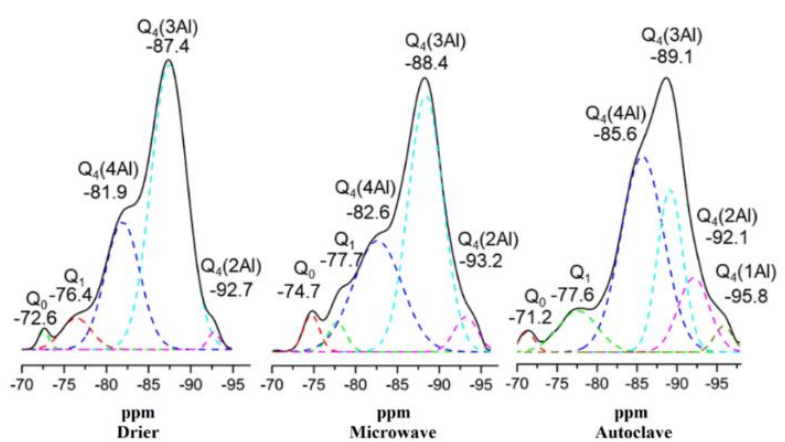

Figure $8{ }^{29} \mathrm{Si}$ NMR spectra of the geopolymer samples cured in drier, microwave, and autoclave conditions

Table 2 Summarizes of ${ }^{29} \mathrm{Si} \mathrm{NMR}$ signals of the different structural types in geopolymeric networks

\begin{tabular}{lcccccc}
\hline Curing regimes & $\mathrm{Q}_{0}$ & $\mathrm{Q}_{1}$ & $\mathrm{Q}_{4}(4 \mathrm{Al})$ & $\mathrm{Q}_{4}(3 \mathrm{Al})$ & $\mathrm{Q}_{4}(2 \mathrm{Al})$ & $\mathrm{Q}_{4}(1 \mathrm{Al})$ \\
\hline Microwave & -74.7 & -77.7 & -82.6 & -88.4 & -93.2 & - \\
Dryer & -72.6 & -76.4 & -81.9 & -87.4 & -92.7 & - \\
Autoclave & -71.2 & -77.6 & -85.6 & -89.1 & -92.1 & -95.8 \\
\hline
\end{tabular}


The ${ }^{29} \mathrm{Si}$ NMR spectra clearly showed the formation of $\left[\mathrm{AlO}_{4}\right]^{5-}$ in the geopolymer structures of all samples. The sample cured in autoclave conditions had the highest amount of $\mathrm{Al}^{3+}$ replacing $\mathrm{Si}^{4+}$ in the structures because of the largest region of $\mathrm{Q} 4(4 \mathrm{Al})$, leading to reduced $\mathrm{pH}$ values and keeping the alumino-silicate networks in stability.

\section{Conclusions}

The geopolymer samples were formed through the pressing process of the roller press and cured in various conditions of the drier, microwave, autoclave (hydrothermal), and at room temperature. The results showed that the compressive strength of all samples exceeded 3.5 MPa, responding to the requirements of TCVN 6477-2012 Vietnamese standard. The various curing conditions affected the engineering properties of the geopolymer samples, such as volumetric weight and mechanical strength. The samples cured at room conditions had slow geopolymerization efficiency after 28 days, and they failed for the softening coefficient. The geopolymer samples cured at $110^{\circ} \mathrm{C}$ using drier and microwave significantly increased in mechanical strength. The samples cured by hydrothermals using autoclaves had high stability on engineering properties and a highsoftening coefficient of up to $90 \%$. This demonstrates that geopolymer-based materials have high water resistance when they are cured using the hydrothermal method using autoclave. Moreover, the geopolymer samples cured using the hydrothermal method also had $\mathrm{pH}$ values less than 9 because the group of $\left[\mathrm{AlO}_{4}\right]^{5-}$ kept the $\mathrm{Na}^{+}$cations better than the $\left[\mathrm{SiO}_{4}\right]^{4-}$ group based on the results of the ${ }^{29} \mathrm{Si} \mathrm{NMR} \mathrm{spectrum.} \mathrm{Thus,} \mathrm{the} \mathrm{more} \mathrm{Q}_{4}(\mathrm{Al})$ bonds are, the higher the ability to hold $\mathrm{Na}^{+}$cations in the aluminosilicate structures of geopolymer. However, the reactions of $\mathrm{Na}^{+}$ions with $\mathrm{CO}_{2}$ filled open pores, increasing the volumetric weight and mechanical strength of the geopolymer samples cured in different conditions. Further research is required to investigate the roles of $\left[\mathrm{SiO}_{4}\right]^{4-}$ and $\left[\mathrm{AlO}_{4}\right]^{5-}$ in reactions with alkaline activators using the analytical tools of NMR, SEM, FTIR, and XRD.

\section{Acknowledgements}

The authors would like to thank Ho Chi Minh City University of Technology (HCMUT), VNU-HCM for their timely support and facilities for conducting this study.

\section{References}

Adam, A.A., Horianto, A., 2014. The Effect of Temperature and Duration of Curing on the Strength of Fly Ash Based Geopolymer Mortar. Procedia Engineering, Volume 95, pp. 410-414

Alas, M., Ali, S.I.A., 2019. Prediction of the High-Temperature Performance of a Geopolymer Modified Asphalt Binder using Artificial Neural Networks. International Journal of Technology, Volume 10(2), pp. 417-427

Alehyen, S., Achouri, M.E., Taibi, M., 2017. Characterization, Microstructure and Properties of Fly Ash-Based Geopolymer. Journal of Materials and Environmental Science, Volume 8(5), pp. 1783-1796

Alonso, S., Palomo, A., 2001. Alkaline Activation of Metakaolin and Calcium Hydroxide Mixtures: Influence of Temperature, Activator Concentration and Solids Ratio. Materials Letter, Volume 47(1-2), pp. 55-62

Ascensão, G., Seabra, M.P., Aguiar, J.B., Labrincha, J.A., 2017. Red Mud-Based Geopolymers with Tailored Alkali Diffusion Properties and pH Buffering Ability. Journal of Cleaner Production, Volume 148, pp. 23-30 
Davidovits, J., 2020. Geopolymer Chemistry and Application. $5^{\text {th }}$ Edition, Institut Géopolymère, France

Do, Q.M., Ngo, P.M., Nguyen, H.T., 2020a. Characteristics of a Fly Ash-Based Geopolymer Cured in Microwave Oven. Key Engineering Materials, Volume 850, pp. 63-69

Do, Q.M., Nguyen, V.U.N., Nguyen, H.T., 2020b. Development of Refractory Synthesized from Waste Ceramic Fiber and Chamotte. Journal of Polymer \& Composites, Volume 8(2), pp. 101-109

Duxson, P., Fernández-Jiménez, A., Provis, J.L., Lukey, G.C., Palomo, A., van Deventer, J.S.J., 2007. Geopolymer Technology: The Current State of the Art. Journal of Materials Science, Volume 42(9), pp. 2917-2933

Duxson, P., Provis, J.L., Lukey, G.C., Separovic, F., van Deventer, J.S.J., 2005. ${ }^{29}$ Si NMR Study of Structural Ordering in Aluminosilicate Geopolymer Gels. Langmuir, Volume 21(7), pp. 3028-3036

Geraldo, R.H., Fernandes, L.F.R., Camarini, G., 2017. Water Treatment Sludge and Rice Husk Ash to Sustainable Geopolymer Production. Journal of Cleaner Production, Volume 149, pp. 146-155

Giannopoulou, I., Panias, D., 2007. Structure, Design and Applications of Geopolymeric Materials. In: 3rd International Conference on Deformation Processing and Structure of Materials, Belgrade, Serbia, pp. 5-15

Horpibulsuk, S., Suksiripattanapong, C., Samingthong, W., Rachan, R., Arulrajah, A., 2016. Durability Against Wetting-Drying Cycles of Water Treatment Sludge-Fly Ash Geopolymer and Water Treatment Sludge-Cement and Silty Clay-Cement Systems. Journal of Material Civil Engineering, Volume 28(1), doi.org/10.1061/(ASCE)MT.19435533.0001351

Janani, S., Santhi, A.S., 2018. Multiple Linear Regression Model for Mechanical Properties and Impact Resistance of Concrete with Fly Ash and Hooked-End Steel Fibers. International Journal of Technology, Volume 9(3), pp.526-536

Lee, M.G., Yi, G., Ahn, B.J., Roddick, F., 2000. Conversion of Coal Fly Ash into Zeolite and Heavy Metal Removal Characteristics of the Products. Korean Journal of Chemical Engineering, Volume 17(3), pp. 325-331

Luukkonen, T., Heponiemi, A., Runtti, H., Pesonen, J., Yliniemi, J., Lassi, U., 2019. Application of Alkali-Activated Materials for Water and Wastewater Treatment: A Review. Review in Environmental Science and Biotechnology, Volume 18, 271-297

Mustafa, A.B.A.M., Kamarudin, H., Hussain, M.B., Rafiza, A.R., Zarina, Y., 2012. Effect of $\mathrm{Na}_{2} \mathrm{SiO}_{3} / \mathrm{NaOH}$ Ratios and $\mathrm{NaOH}$ Molarities on Compressive Strength of Fly-Ash-Based Geopolymer. ACI Materials Journal, Volume 109(5), pp. 503-508

Nguyen, H.T., 2020a. Geopolymerization: A Review on Physico-Chemical Factors Influence to the Reaction Process. Journal of Polymer \& Composites, Volume 8(2), pp. 128-137

Nguyen, H.T., 2020b. Novel Porous Refractory Synthesized from Diatomaceous Earth and Rice Husk Ash. Journal of Polymer \& Composites, Volume 8(2), pp. 128-137

Nguyen, H.T., 2021. Microstructure Stability and Thermal Resistance of Ash-Based Geopolymer with Sodium Silicate Solution at High Temperature. International Journal of Engineering Research in Africa, Volume 53, pp. 101-111

Nguyen, H.T., Dang, T.P., 2021. Fly Ash-Based Geopolymer: Green Material in CarbonConstrained Society. Solid State Phenomena, Volume 321, pp. 65-71

Nguyen, H.T., Dang, T.P., Pham, M.T., Le, V.Q., 2021a. Engineering Properties of AlkaliActivated Materials Produced from Thu Duc Water Plant Waste Sludge, Fly Ash, and Alkaline Activator by Semi-dry Pressing Method. Journal of Polymer \& Composites, Volume 9(1), pp. 39-48 
Nguyen, H.T., Nguyen, V.P., Do, Q.M., 2021b. Effects of Curing Time to Engineering Properties of Alkaline-Activated Materials Synthesized from Thu Duc Water Plant Waste Sludge, Fly Ash, and Geopolymer Aggregate. Materials Science Forum, Volume 1029, pp. 111-117

Novais, R.M., Buruberri, L.H., Seabra, M.P., Labrincha, J.A., 2016. Novel Porous Fly-Ash Containing Geopolymer monoliths for Lead Adsorption from Wastewaters. Journal of Hazardous Materials, Volume 318, pp. 631-640

Numanuddin M.A., Samarakoon S.M.S.M.K., 2021. Utilization of Industrial ByProducts/Waste to Manufacture Geopolymer Cement/Concrete. Sustainability, Volume 13(2), ID 873

Palomo, A., Alonso, S., Fernandez-Jiménez, A., Sobrados, I., Sanz, J., 2004. Alkaline Activation of Fly Ashes: NMR Study of the Reaction Products. Journal of American Ceramic Society, Volume 87(6), pp. 1141-1145

Panias, D., Giannopoulou, I.P., and Perraki, T., 2006. Effect of Synthesis Parameters on the Mechanical Properties of Fly Ash-Based Geopolymers. Colloids and Surfaces A: Physicochemical and Engineering Aspects, Volume 301(1-3), pp. 246-254

Petrus, H.T.B.M., Olvianas, M., Astuti, W., Nurpratama, M.I., 2021. Valorization of Geothermal Silica and Natural Bentonite Through Geopolymerization: A Characterization Study and Response Surface Design. International Journal of Technology, Volume 12(1), pp. 195-206

Poowancum, A., Nimwinya, E., Horpibulsuk, S., 2015. Development of Room Temperature Curing Geopolymer from Calcined Water-Treatment-Sludge and Rice Husk Ash. Calcined Clays for Sustainable Concrete, Volume 10, pp. 291-297

Prasanphan, S., Wannagon, A., Kobayashi, T., Jiemsirilers, S., 2019. Reaction Mechanisms of Calcined Kaolin Processing Waste-Based Geopolymers in the Presence of Low Alkali Activator Solution. Construction and Building Materials, Volume 221, pp. 409-420

Protsak, I.S., Morozov, Y.M., Dong, W., Le, Z., Zhang, D., Henderson, I.M., 2019. A ${ }^{29}{ }^{-} \mathrm{i}$, ${ }^{1} \mathrm{H}$, and ${ }^{13} \mathrm{C}$ Solid-State NMR Study on the Surface Species of Various Depolymerized Organosiloxanes at Silica Surface. Nanoscale Research Letters, Volume 14(160), pp. 115

Rim, G., Marchese, A.K., Stallworth, P., Greenbaum, S.G., Park, A.H.A., 2020. ${ }^{29}$ Si Solid State MAS NMR Study on Leaching Behaviors and Chemical Stability of Different Mg-silicate Structures for $\mathrm{CO}_{2}$ Sequestration. Chemical Engineering Journal, Volume 396, doi.org/10.1016/j.cej.2020.125204

Schoonheydt, R.A., Johnston, C.T., Bergaya, F., 2018. Clay Minerals and Their Surfaces. Developments in Clay Science, Volume 9, pp. 1-21

Silva, I.C.E., Gomes, J.C., Albuquerque, A., 2010. Study of the Structural Stability, pH Variation in Water and Influence of the Curing Conditions on Mechanical Resistance of Mineral Wastes Geopolymeric Artificial Aggregates (WGA) as Alternative Materials for Wastewater Treatment Processes. Silesian University Technology, Volume 3, pp. 121128

Sudibandriyo, M., Putri, F.A., 2020. The Effect of Various Zeolites as an Adsorbent for Bioethanol Purification using a Fixed Bed Adsorption Column. International Journal of Technology, Volume 11(7), pp. 1300-1308

Suksiripattanapong, C., Srijumpa, T., Horpibulsuk, S., Sukmak, P., Arulrajah, A., Du, Y.J., 2015. Compressive Strengths of Water Treatment Sludge-Fly Ash Geopolymer at Various Compression Energies. Lowland Technology International, Volume 17(3), pp. 147-156 
Susanto, H., Fahmi, Y., Hutami, A.T., Hadi, Y.T., 2020. Effects of Fly Ash Loading on the Characteristics of PVC-Based Cation Exchange Membranes for Reverse Electrodialysis. International Journal of Technology, Volume 11(3), pp. 544-553

Swanepoel, J.C., Strydom, C.A., 2002. Utilisation of Fly Ash in a Geopolymeric Material. Applied Geochemistry, Volume 17(8), pp. 1143-1148

Waijarean, N., Asavapisit, S., Sombatsompop, K., MacKenzie, K.J.D., 2014. The Effect of the $\mathrm{Si} / \mathrm{Al}$ Ratio on the Properties of Water Treatment Residue (WTR)-Based Geopolymers. Key Engineering Materials, Volume 608, pp. 289-294

Waijarean, N., Asavapisit, S., Sombatsompop, K., 2013. Strength and Microstructure of Water Treatment Residue-Based Geopolymers Containing Heavy Metals. Construction and Building Materials, Volume 50, pp. 486-491

Zhang, Y., Sun, W., Li, Z., 2008. Infrared Spectroscopy Study of Structural Nature of Geopolymeric Products. Journal of Wuhan University Technology-Materials Science, Volume 23(4), pp. 522-527 